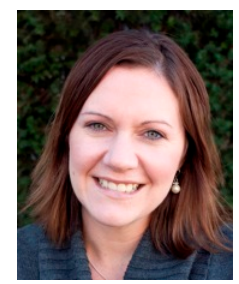

\title{
Guest Editor's Note: My Thoughts on CALL at the AEC
}

Using technology purposefully in the classroom enhances the learning experience for today's digital natives, assists the instructor in addressing $21^{\text {st }}$ century learners, and engages students in taking ownership of the learning process. That being said, if technology fails, how much of this is true? In my personal experience, some of the main concerns teachers often have with using technology circle around the idea that there simply is not enough time to use, evaluate and re-think new technology. Over the last year, while teaching and training other teachers to use technology to enhance the classroom experience, I have heard countless stories of triumphs and failures. From a professional development perspective, both triumphs and failures are considered success in that growth and development are achieved through positive and negative experiences. If you are uneasy about using new technology, I would advise that you keep it simple. Be kind to yourself and initiate an uncomplicated approach in your attempt to reach a $21^{\text {st }}$ century learner through dynamic, engaged instruction that uses technology as a lever, not a crutch.

There are a few technology specific programs utilized at the AEC that lend themselves to better practice. And they work. Some of the current programs utilized at the AEC for student projects and classroom enrichment featured in this special CALL issue include: Google Drive (specifically Google docs), VoiceThread, and Blackboard features. Although there are hundreds of applications, programs, and software available to use, spotlighting these three items is beneficial specifically to AEC teachers. For more information and examples, please visit our AEC Teacher Resources Blackboard, a place designed with you in mind, and follow our AEC CALL group on Facebook.

Thank you,

Summer Peixoto 